Journal in the shape of the proceedings of the Scottish Otological and Laryngological Society, to which we offer our most hearty good wishes.

\title{
THE EDUCATION OF THE SPECIALIST IN LARYNGOLOGY RHINOLOGY, AND OTOLOGY.
}

\section{a Plea for Graduation on a Broad Basis.}

The Presidential Address at the opening of the Session 1910-11 of the Laryngological Section of the Royal Society of Medicine.

By P. Watson Williays, M.D.Lond., etc.,

President of the Section of Laryngology and Vice-President of the Section of Otolory ; in charge of Department for Diseases of Nose, Throat, and Ear, Bristol Royal Infirmary ; Lecturer on Rhinology and Laryngology, University of Bristol, ete.

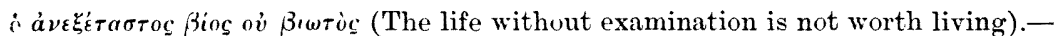

Plato.

Gentlemen,-In electing me as President of the Laryngological Section of the Royal Society of Medicine, I am conscious that you have paid me the highest honour that it is in your power to bestow. I wish sincerely I could feel equally conscious of being worthy to follow my two distinguished predecessors in office. Of one thing, however, I am certain, that is, the pervading harmony which exists between the members of this Section, amongst whom criticisms are offered with only the friendly desire to help one another in points of difficulty, or to advance knowledge in this special branch of medical science, and it will be my constant aim to maintain this spirit of confraternity.

Coming from Bristol, where, as you are aware, we have recently developed a University, my thoughts have perforce been turned in the direction of educational matters, and as a lecturer on diseases of the nose, throat, and ear, I have given much consideration to the position of our own speciality in medical education, which in the interests of practitioners and of patients leaves something to be desired.

We hear it said that this is a day of specialism, and specialism in medicine and surgery is thought to be a modern development. Yet we learn from the Ebers' papyrus that in the thirteenth century B.c. patients applying for relief to the medical temple at Thebes had to state their complaint, and that it was left to the principal of the medical staff to send the specialist best suited for 
the case. ${ }^{1}$ We find that the practice of surgery was distinguished from medicine even earlier than the thirteenth century B.c., and it is recorded that in Egypt each physician treated a single disorder and no more, some devoting themselves to the eye, others to the teeth (they made artificial teeth, and some have asserted that they have found traces of gold stoppings in the mummies), and others, again, devoted themselves to disorders of the intestines, while yet others were obstetric physicians called in by midwives to the difficult cases.

In our own land, when in 1460-61 a charter was granted to the Barber Surgeons, and the Edinburgh Charter was obtained in 1505 , surgery in a humble way started on its career divorced from medicine, and under the paternal fostering of the College of Surgeons became a science and art distinct from internal medicine.

We find in consequence that in Great Britain, and later also in Ireland, the field of medical science was long occupied by rival schools of medicine and of surgery; hence arose onr academic distinction between medicine and surgery peculiar to this country, for in practically every European nation except our own a certain course of study is laid down, and for all their practitioners, State examinations must be passed. If a degree is obtained, it is always that of doctor of medicine; there is no distinct qualification in surgery, and it is the same in Canada and the United States. After qualifying on a common basis, the graduate is free to follow his own bent, and if he seeks to become a pure physician, surgeon, or specialist, he must establish himself as such, not by passing further examinations, but by his clinical and research work. Thus, while the degree of M.D. serves for all physicians, surgeons, and specialists alike, their subsequent differentiation is clinical and not academical as with us.

We alone carry examinations quite beyond the qualifying stage to the higher standards of medicine and surgery, and he who aspires to the charge of a teaching clinic and consulting practice must, as a rule, first obtain a higher and special qualification in medicine or in surgery respectively, involving a further and more advanced course of study. Though not without drawbacks, this has the advantage of ensuring that the more highly qualified physician or

\footnotetext{
1 It would appear that only a few of the students remained to the end of their medical course at Thebes, the most rifted being then sent to the celebrated faculty of Heliopolis, whence they returned to Thehes, where they became physicians to the Court, and, attuched to some priestly college, were consulted in serious cases._-" Carda," i, p. 32, Ebers.
} 
surgeon has received, over and above what is necessary for qualification, a very thorough grounding in current medical or surgical science and all that immediately pertains to it, and the custom has coincided with an increasingly high standard of original medical and surgical work in this country. The plan has answered so long as the whole range of medicine on the one hand, or of surgery on the other, could be mastered by one individual ; but with advancing knowledge pure medicine and surgery are no longer the only specialities, and with the growth and development of newer special branches the objections to our English system appear. Either we must continue our unfortunate custom of mentally placing each speciality under the category of medicine or of surgery, and of demanding as the sine quin non for teaching clinics the corresponding medical or surgical qualification, although it may have no special bearing whatever on the specialities in question (in my own hospital both the laryngologist and the obstetrician of the future are distinguished in that they will have to possess all the higher qualifications both of the physicians and of the surgeons), or we must be consistent, and offer opportunities for a qualified practitioner taking his higher qualification in lis speciality, after a course of post-graduate study and practice parallel to that required for the physician or the general surgeon.

No one could be more opposed to too early or too narrow specialisation than $\mathrm{I}$ am, for it is certain that a sound up-bringing in the whole range of general medicine and surgery is the only safe foundation for any special branch. But the tendency is to make another speciality-general surgery-the academic test of fitness in laryngology, while medicine, and even systematic training in our department is made a secondary consideration with a consequent danger of our becoming too exclusively surgical. In no other speciality would this be more deplorable than our own, for which I believe general practice is as good taking-off ground as pure surgery. We want contributions from all points of view, and it should always be open to every practitioner to specialise in any direction according to his opportunities for so doing.

'To our fellow-countryman, Robert Liston, belongs the honour of publishing, ${ }^{1}$ in 18:37, directions for laryngoseopy, which he

${ }^{1}$ Liston, "Practical Surgery," London, 1837, p. 350: "The existence of this swelling can often be ascertained by careful examination with the finger, and by means of a speculum; by such a glass as is used hy dentists on a long stalk, previously dipped in hot water, introduced with its reflecting surface downwards and carried well back into the fauces, a view may often be had of the parts." 
recommended and employed for observing diseases in the larynx; eighteen years later Manuel Garcia published his epoch-making observations, to be followed by those early giants in our speciality, 'Turck and Czermak, while so many of those who are here to-day have had the privilege of personal acquaintance with the slightly later but hardly less distinguished pioneers, when laryngology was still in its infancy, and many members of this Section have nut only witnessed, but have generously contributed to, its exceedingly rapid growth and development. Indeed, most of us have had to acquire our knowledge to a large extent first-hand, and it has not always been easy to keep so thoroughly in touch with the rapid advances all the world over.

But things are very different from what they were when I started practice, and hardly any individual is capable of a complete mastery of the whole range of rhino-laryngology, and if otology be superadded the grouud is so extensive that, without devoting his whole time and attention to these subjects over several years, no one can hope to be a scientific expert throughout such a large territory.

It is no small matter to acquire an accurate knowledge of anatomy, pathology, and, in so far as they bear on the diseases of the nose, throat, and ear, of neurology and general medicine, the ætiology, diagnosis, and treatment of diseases of these, together with a fair acquaintance with the varions methods of treatment and operations which have been, or are, employed, as well as the acquirement of the operative and diagnostic technique, including the trachea and cesophagus, for it is to the honour of our speciality that our laryngological colleagues abroad, where the development of specialities has been better fostered, have originated and made practical tracheoscopy, bronchoscopy, and oesophagoscopy.

I think no one who is not iguorant of the work that is being done by laryngologists and otologists ean deny that, as an ardition to that sound general edncation in the principles of medicine and surgery for pass qualifications, all this involves as much, if not more, study as is demanded of those who present themselves for a Fellowship of the Royal Colleges of Surgeons or a mastership of surgery at a university, or an M.D. in obstetric medicine, in State medicine or in pathology, or an M.S. in dental surgery.

All these degrees in special branches may be acquired at the London University, and I sincerely hope that, on similar lines, a graduate may ere long be able to take a higher degree in our speciality. Surely the practitioner who so qualified himself for 
work in laryngo-otology should have the opportunity of being tested by examination and of obtaining his higher degree in this department. He would be better equipped for making the utmost use of his riper clinical experience than by devoting himself instead to accuiring an exact knowledge of the anatomy of the whole body and the whole range of advanced medicine or general surgery, nisually at the expense of systematir liberal study of his speciality and all that pertains to it. To test such study by examination too late in life would be a grave misfortune. Already the tendency in this comtry is to continue medical examinations unduly, and thus to trench too far on the precious years of early adult life, when a man's best original ideas are germinating and should be cherished and allowed spontaneous growth, instead of being trammelled and choked ont of life by scientific pedagogy, as though Plato had stated that "life without paminations was not worth living."

We gather fruits in antumn, but life's spring is the sowing time. It is worse than useless to spend too long a time in tilling and preparing the ground, and still worse to disturb the roots by examination when we should be looking for blossoms of early research. There is more truth in the world-renowned Oslerism than is generally suspected, and particularly in the field of science; it is an open question whether, even before forty, one's mind ever. breaks new ground in the sense of being original.

\title{
DEAFNESS AND DISEASES OF THE EAR IN RELATION TO THE PUBLIC SERYICES AND INSURANCE, AND THEIR BEARING ON FORENSIC CASES AND THE CHOICE OF A MEANS OF EARNING AIYELIHOOD.
}

\author{
By Jobson Horne, M.D., \\ Surreon to the Metropolitan Ear, Nose, and Throat Hospital; \\ formerly Ernest Hart Scientific Research Scholar of \\ the British Medical Association.
}

THE length of the title of this paper is out of all proportion to the length of time officially allotted for the reading of it. I do not for one moment suggest that the title should be curtailed, and it is still further from my intentions to trespass upon the time available for the discussion of the subject. The subject covers a considerable amount of ground, and is one about which there is undoubtedly room for more than one opinion; in short, it lends itself to discus- 